\title{
udancas climáticas globais: a resposta da educação
}

Pedro Roberto Jacobi

Universidade de São Paulo

Antonio Fernando S. Guerra

Universidade do Vale do Itajaí

Samia Nascimento Sulaiman

Universidade de São Paulo

Tiago Nepomuceno

Universidade de São Paulo

\section{Introdução}

A célebre frase de Yuri Gagarin, "A Terra é azul", em 1961, a fantástica imagem da Terra vista da Lua de Galen Rowell, no Natal de 1968, e a poética e apaixonada declaração de amor ao planeta de Caetano Veloso ao compor Terra contrastam com a imagem da Agência Espacial Americana (NASA), de 14 de dezembro de 2009, desse mesmo planeta envolto por uma nuvem de partículas, o carbono negro' (black carbon), um dos efeitos das mudanças climáticas.

$\mathrm{O}$ efeito estufa - um fenômeno natural que preserva a vida no planeta há bilhões de anos - vem acelerando

1 Imagem disponível em: <http://www.nasa. gov/multimedia/imagegallery/image_feature_1546.html>. 
as mudanças climáticas, e já tem um de seus principais agentes identificado pela ciência e tecnologia. O aumento dos sintomas do aquecimento global, causados pela concentração e aumento dos GEE - gases que provocam o "efeito estufa" -, coincide com a queima de combustíveis fósseis a partir da Revolução Industrial.

Ainda que o Painel Intergovernamental de Mudanças Climáticas ${ }^{2}$ (Intergovernamental Panel Climate ChangeIPCG) tenha sido criado em 1988, seus relatórios ${ }^{3}$ só passaram ao domínio da opinião pública após a divulgação pelas mídias de alguns de seus dados e cenários futuros quanto ao aumento dos $\mathrm{GEE}^{4}$ e o aquecimento global, caso medidas não fossem tomadas pelos governos e sociedade. Apesar da corrente dos ceticistas, que negam o aquecimento global, e da polêmica sobre a suspeita de manipulação de alguns dados dos relatórios, não há mais argumentos científicos que neguem que um dos agentes dessas mudanças é o próprio ser humano.

Conforme o relatório "Estado da população no mundo", do Fundo de População das Nações Unidas (UNFPA),

2 O IPCG foi criado por iniciativa da Organização Meteorológica Mundial (WMO) e do Programa das Nações Unidas para o Meio Ambiente (PNUMA). Seu objetivo era organizar uma base de dados com informações técnicas, científicas e socioeconômicas sobre o fenômeno do aquecimento global (Lückman, 2007). O relatório representa o resultado de cinco anos de estudos realizados por cientistas de vários países.

3 Disponíveis em: <http://mudancasclimaticas.cptec.inpe.br/>

4 A queima de combustíveis fósseis é responsável por mais de $75 \%$ das emissões de $\mathrm{CO}$ na atmosfera. A ocupação e o uso do solo, desmatamento e degradação de florestas são responsáveis pelo restante. de novembro de 2009, a mudança climática é muito mais do que emissões de gases que provocam o efeito estufa. A influência da atividade humana sobre o clima é complexa: diz respeito ao que consumimos, ao tipo de energia que produzimos e utilizamos, se vivemos na cidade ou em uma fazenda, em um país rico ou pobre, se somos jovens ou velhos, o que comemos e, até mesmo, tem relação com a igualdade de direitos e oportunidades desfrutada por mulheres e homens. O efeito das mudanças climáticas dispara as migrações, destrói os meios de sustento, altera as economias, debilita o desenvolvimento e exacerba as desigualdades entre os sexos.

Diante dos efeitos dos fenômenos naturais, denominados pelos governos e mídias de "tragédias ou desastres naturais", e do fracasso da Conferência de Cúpula sobre Mudança Climática em Copenhague, em dezembro de 2009, convém à espécie humana, e também aos pesquisadores e pesquisadoras em educação da ANPEd, um olhar mais atento sobre os efeitos e vulnerabilidades a que todos estamos expostos diante das mudanças climáticas globais e sobre os desafios que se colocam aos educadores para conter e minimizar a crise ambiental que vem acelerando essas mudanças. É uma questão de responsabilidade e cidadania global.

O Brasil não está imune aos efeitos das mudanças globais. Não há consenso em relação ao sinal das anomalias para a Amazônia e o Nordeste brasileiro, quanto à precipitação. No entanto, essas mudanças climáticas têm um impacto nos ecossistemas naturais e especificamente na distribuição de biomas, e por extensão na biodiversidade, na agricultura, nos recursos hídricos. O que aponta o "Relatório 
n. 6 de mudanças climáticas e possíveis alterações nos biomas da América do Sul" (Nobre et al., 2007) é a combinação sinérgica dos impactos climáticos regionais decorrentes dos desmatamentos, dos resultantes do aquecimento global implicando climas mais quentes, e possivelmente também mais secos, e da maior propensão a incêndios florestais. Cenário este que amplifica a vulnerabilidade dos ecossistemas tropicais e pode levar à savanização de partes da Amazônia e desertificação do Nordeste brasileiro.

Em contrapartida, Sudeste e Sul do Brasil têm sofrido os efeitos de chuvas fortes e enchentes. O estado de Santa Catarina, especialmente a região do Médio Vale e da foz da bacia do rio Itajaí, foi palco de um desses "desastres ambientais", em novembro de 2008, provocado por enchentes e desmoronamentos de encostas de morros, atingindo em torno de sessenta cidades e afetando mais de 1,5 milhões de pessoas. Outros casos como esse, com centenas de vítimas fatais, se repetiram em 2010, nos estados do Rio de Janeiro, São Paulo, Bahia e Espírito Santo.

O elevado número de mortes e milhares de "refugiados ambientais", que ainda vivem em abrigos públicos em algumas dessas cidades, bem como os prejuízos socioeconômicos, ambientais e na infraestrutura dos municípios e dos estados nos levam a acreditar que essas tragédias poderiam ter sido amenizadas se: por um lado, a educação ambiental sobre as questões da sustentabilidade, vulnerabilidade e efeitos das mudanças climáticas fossem discutidas na formação docente e nas escolas. E, por outro lado, vidas teriam sido preservadas se a legislação e gestão ambiental fossem cumpridas, evitando a destruição da mata ciliar nas margens dos rios, as ocu- pações irregulares nas regiões urbanas, morros e Áreas de Preservação Permanente (APP) e Unidades de Conservação (UC), que agravam os problemas ambientais.

$\mathrm{Na}$ abordagem das questões das mudanças climáticas, há que se tomar cuidado em não alimentar representações e discursos catastrofistas, ou com tons apocalípticos de seitas que indicam suas causas como atos de vingança divina ou da própria natureza sobre o ser humano. Ao mesmo tempo, é comum as pessoas se sentirem paralisadas ou confusas com a avalanche de informações, assumindo posições comodistas do tipo: "O que eu posso fazer, se sempre foi assim?" É necessário superar tanto o fatalismo quanto a inércia, como se os fatos refletissem um poder superior, resultando numa imobilidade, em que a realidade é vista como imutável, uma "[...] impossibilidade de fazer algo diante do poder dos fatos, sob os quais fica vencido o homem" (Freire, [1964] 2007, p. 114). Ao contrário, a formação da consciência crítica remete-nos à reflexão e ação sobre os fatos, para transformar essa realidade, ao invés da paralisação diante deles.

O grande desafio da mudança cultural para a mobilização ante as mudanças climáticas está, portanto, na não percepção das conexões existentes entre nossas opções cotidianas de locomoção, a emissão de gases de efeito estufa e o consequente aumento da temperatura da Terra; entre o desmatamento da Amazônia e da Mata Atlântica e a desertificação em partes do Sul do país; a quantidade de resíduos produzidos e o aumento do nível dos oceanos; o assoreamento dos rios, a impermeabilização de solos e as enchentes; o consumo desenfreado e o esgotamento dos recursos naturais. 


\section{Mudanças climáticas: uma análise transnacional de práticas educativas}

A International Alliance of Leading Education Institutes (IALEI) desenvolveu, entre 2008 e 2009, pesquisa sobre o tema "Mudança Climática e Desenvolvimento Sustentável: a resposta da educação", envolvendo dez diferentes países, ${ }^{5}$ entre eles o Brasil, representado pela Faculdade de Educação da Universidade de São Paulo (FE-USP) por meio do TEIA-USP Laboratório de Educação e Ambiente, que elaborou texto sobre a realidade brasileira (Jacobi et al., 2009).

A IALEI produziu um relatório global (IALEI, 2009), como resultado da síntese dos dez relatórios, e destacou quatro questões estruturais. Destas, três diziam respeito à educação para o desenvolvimento sustentável de maneira mais ampla, mas uma em especial procurava abordar o papel da educação perante a urgência das alterações do clima, tendo sido formulada da seguinte maneira: "Pode a educação contribuir com o desafio de lidarmos com a necessidade de mitigação e adaptação às mudanças climáticas? Se sim, como se daria tal contribuição e como esta influenciaria a educação para o desenvolvimento sustentável e vice-versa?" (idem, p. 7). Para a IALEI, as mudanças climáticas representam, do ponto de vista pedagógico, um desafio único para que se teste "a capacidade de se organizar a aprendizagem em torno de problemas caracterizados por dinâmicas sociais complexas, conhecimento incerto e riscos" (idem, p. 14).

África do Sul, Austrália, Brasil, Canadá, China, Coreia do Sul, Dinamarca, Estados Unidos, Reino Unido e Cingapura.
Um apontamento recorrente nos relatórios dos países desenvolvidos é o fato de só nos últimos anos a CCE (Climate Change Education, Educação para as mudanças climáticas) ter começado a desenvolver uma identidade própria, o que revelaria o quanto esta questão ainda se encontra no seu início. Em alguns países, por exemplo, é o poder público que tem assumido a tarefa de levar adiante, no âmbito da educação, o tema das mudanças climáticas. É esse o caso de países como Austrália, Canadá, Dinamarca e China, cujos governos - com diferentes níveis de protagonismo - vêm promovendo diversas iniciativas educacionais focadas no aquecimento global e suas consequências. Mas há outros modelos de atuação menos centralizados, como por exemplo o Brasil, onde o Estado compartilha com inúmeros outros atores sociais ${ }^{6}$ o protagonismo nesse campo de atuação, particularmente pelo ativismo de organizações não governamentais e iniciativas empresariais.

Independentemente do nível de envolvimento e centralização pelos governos, os relatórios frisam que a CGE segue sendo um tema periférico na área da educação, tanto no âmbito das pesquisas acadêmicas quanto na prática

\footnotetext{
6 É o caso das contribuições do GT Educação: Educação Ambiental, Mobilização Política e Popular para a Cultura da Sustentabilidade e as Mudanças Climáticas do Fórum Brasileiro de ONGs e Movimentos Sociais para o Meio Ambiente e o Desenvolvimento (FBOMS) (2007); Fóruns de Mudanças Climáticas da Região Sul - Fóruns Sul (2009); Propostas das Centrais Sindicais sobre a questão climática, preparatória para a conferência em Copenhague (2009); e do texto base elaborado pelo WWF Brasil, Instituto Ecoar e redes de Educação Ambiental, divulgado no VI Fórum Brasileiro de EA, no Rio de Janeiro (2009).
} 
cotidiana escolar. Ainda é amplamente identificado como um tema que merece ser abordado privilegiadamente de uma perspectiva cientificista, como se perspectivas outras, distintas do olhar das hard sciences, nada tivessem a contribuir no seu enfrentamento.

$\mathrm{Na}$ terminologia europeia, EE (Environmental Education, Educação Ambiental) é um conceito bastante distinto de ESD (Education for Sustainable Development, Educação para o Desenvolvimento Sustentável). Ambos representariam correntes educacionais focadas na questão ambiental; mas com o diferencial de que a ESD estaria comprometida com o empoderamento dos educandos a fim de que estes se revelem protagonistas nas ações e tomada de decisões, ao passo que a EE representaria uma visão mais estreita e instrumental fundamentada estritamente na divulgação de conhecimentos científicos e tendo em vista a mudança de comportamentos (idem, p. 15). ${ }^{7}$ Neste sentido é que o relató-

Vale lembrar que em outras regiões do globo (como a América Latina e países lusófonos) a terminologia educação ambiental (EE em inglês) não traz obrigatoriamente consigo a pecha de cientificista e comportamentalista. No Brasil, ao contrário, tanto o discurso das políticas públicas como do Programa Nacional de Educação Ambiental (PRONEA) (Brasil, MEG, MMA, 2005), quanto de boa parte do setor acadêmico no campo ambiental, consideram inerente à EA a perspectiva crítico-emancipadora (Loureiro, 2004; Loureiro; Layrargues; Castro, 2006) que, ao menos na terminologia europeia, como citamos, representaria a educação para o desenvolvimento sustentável (ESD em inglês), segundo a década (2005-2014) instituída pela UNESCO. Há, portanto, um claro antagonismo e conflito conceitual e ideológico em jogo, desvelado em artigos como de Diegues (1992), Meira e Sato (2005), Gaudiano (2006), Freitas (2007), Gadotti (2008), Gaudiano e Cartea (2009). rio aponta que, de maneira geral, nos diferentes países que participaram da pesquisa, as práticas da CCE se situam entre essas duas correntes, a EE e a ESD. A IALEI chama ainda a atenção para o fato de que alguns países, como Dinamarca e Cingapura, apontaram que, nas políticas climáticas estabelecidas pelos seus governantes, a educação se destaca pela sua ausência, na medida em que ministérios outros que não o da Educação estão mais diretamente empenhados na determinação dessas políticas.

Os relatórios nacionais apontaram três possibilidades que, grosso modo, indicam os caminhos mais prováveis para o seu desenvolvimento (idem, ibidem). São eles:

Cenário 1: Em países como a China e os Estados Unidos, há uma forte tendência de que a GCE se desenvolva de forma independente da educação ambiental, tornando-se um tema próprio no campo da educação. Nos Estados Unidos, a CCE vem sendo interpretada como "educação acerca da compreensão científica das mudanças climáticas globais". Na China, contudo, há nisso uma contradição muito clara, uma vez que, enquanto a CGE foca atividades de popularização do conhecimento científico, os demais temas da educação ambiental (ESD) são abordados por meio de quatro princípios básicos muito mais amplos: educação de valores, abordagem holística e interdisciplinar, aumento da diversidade e das competências, criatividade nas pesquisas.

Cenário 2: Já na Austrália, Reino Unido, Coreia do Sul e Cingapura, a tendência da CCE é a de se desenvolver como parte integrante da EA, tornando-se um tema interdisciplinar tendência esta que naturalmente se 
apoia nas mais distintas abordagens conforme cada país; especialmente pelo fato de a educação ambiental não ser uma categoria exata e igualmente compartilhada por todos os envolvidos nesta pesquisa.

Cenário 3: O relatório dinamarquês apontou ainda um terceiro cenário que representaria um híbrido entre os dois anteriores. Neste, a CCE se estabeleceria como um elemento independente, mas ainda localizado no campo da educação ambiental.

Cenários à parte, mereceu destaque a preocupação expressa pelo relatório britânico quanto ao risco de a CGE reduzir a importância de iniciativas educativas mais abrangentes para promover o desenvolvimento sustentável, em razão do imenso potencial dramático das transformações climáticas (como os ciclones, tempestades, enchentes). A atenção até então focada nos distintos temas tratados pela educação ambiental tem reduzido tudo a questões como emissão de carbono, reciclagem e transportes "em detrimento dos objetivos holísticos da educação ambiental (como, por exemplo, encorajar o pensamento crítico e a participação democrática)" (idem, ibidem). Se assim for, alertam os britânicos, a educação ambiental (ESD) estaria dando um passo na direção errada.

No que diz respeito às principais barreiras para a implantação e desenvolvimento tanto da CCE quanto dos demais temas relacionados à ESD, os relatórios apontaram como os principais desafios postos:

1 A educação como uma ferramenta fundamental para a manutenção e/ou incremento do poderio econômico. No atual cenário de acirrada competitividade econômica global, há em muitos países a tendência de se privilegiar como foco de aprendizagem as disciplinas científicas em detrimento de outras preocupações, dentre as quais os temas ambientais. Os relatórios da China, Dinamarca, Coreia do Sul, Cingapura e Reino Unido apontaram esse aspecto.

2 A distância entre o que as políticas públicas determinam e a prática concreta no ambiente escolar. A Austrália destacou-se como uma honrosa exceção nesse aspecto, uma vez que seu relatório apontou que "há uma boa conexão entre o que é determinado nos documentos políticos australianos e as iniciativas que têm sido colocadas em prática” (idem, p. 21).

3 A falta de preparo dos docentes diante de temas tão complexos quanto a CCE. Todos os dez países afirmaram que lhes faltam professores suficientemente preparados para que a questão ambiental possa ser trabalhada com a devida competência que o tema exige.

4 O fato de se trabalhar a ESD numa perspectiva estritamente científica e comportamentalista. Essa abordagem, bastante presente no ensino escolar, deixa de reconhecer e valorizar o enorme potencial de questões que se enquadram mais no âmbito da cidadania e da ética a partir de uma perspectiva crítica. 
É também interessante explicitar que os relatórios apontam diferenças entre os países de maneira geral, e não - como talvez fosse de esperardiferenças padronizadas entre os países mais ricos e os países de recente industrialização. Nesse sentido, como apontam Gaudiano e Cartea (2009), a principal barreira para a mudança social, no que diz respeito à complexa natureza estrutural do problema das mudanças climáticas, é que:

[...] existem obstáculos de ordem moral, sócio-política, cultural, sócio cognitiva e psicossocial que condicionam a representação social por parte da população, e dificultam a adoção de mudanças significativas nos estilos de vida, individuais e coletivos, relacionados com as atividades humanas que desequilibram o clima. (Gaudiano; Cartea, 2009, p. 6)

\section{O tema das mudanças climáticas na educação ambiental brasileira}

A Política Nacional de Meio Ambiente (PNMA) de 1981 e a Constituição Federal de 1988 estabeleceram a necessidade da promoção da educação ambiental em todos os níveis de ensino, tendo como princípio um enfoque humanista, holístico, democrático e participativo, enfatizando uma concepção de meio ambiente baseada na interdependência entre o meio natural, o socioeconômico e o cultural. A discussão legislativa acerca de uma Política Nacional de Educação Ambiental (PNEA) teve início já em 1993, e no ano seguinte foi criada a primeira versão do Programa Nacional - PRONEA, que previa a capacitação de gestores e educadores e o desenvolvimento de ações educativas, instrumentos e metodologias dedicados a diferentes linhas de ação em educação ambiental.

A questão ganha representatividade institucional e como política pública no período de 2003 a 2009, dada a articulação entre o Ministério da Educação (MEG) e o Ministério do Meio Ambiente (MMA), promovendo a instalação do Órgão Gestor (OG) da PNEA, criado com a regulamentação da lei n. 9.795/99 pelo decreto n. 4.281/2002. Essa iniciativa e outras como o edital do Fundo Nacional de Meio Ambiente para diagnóstico da EA em alguns estados e regiões, coordenado pela Rede Brasileira (REBEA), e de alimentação do Sistema Brasileiro de Informações em Educação Ambiental (SIBEA); a instalação das Comissões Interinstitucionais de Educação Ambiental (CIEAs) ${ }^{8}$ nos estados, dentre outras, foram decisivas para a execução das ações de educação ambiental no âmbito do governo federal, das políticas estaduais e municipais, e na educação formal e não formal. O OG e seu Comitê Assessor têm como seu referencial programático o "Tratado de Educação Ambiental para Sociedades Sustentáveis e Responsabilidade Global" - aprovado pelo Fórum Global das Organizações Não Governamentais (ONGs), paralelo à Rio 92 - e a segunda versão do PRONEA (Brasil, MEG, MMA, 2005).

8 As CIEAs são colegiados estaduais que têm por missão geral propor as diretrizes da Política e do Programa Estadual de Educação Ambiental. São constituídos por representantes do poder público e da sociedade civil e já existem em quase todos estados do país e no Distrito Federal. 
Entre outras iniciativas no campo, a construção da Agenda 21 nas Escolas tem propiciado espaços de participação em defesa do meio ambiente e de diálogo com estudos das Agendas 21 Global, Brasileira, Estadual e Local para intervenção tanto nos recintos escolares como no meio familiar e social. A Comissão de Meio Ambiente e Qualidade de Vida nas Escolas (COM-VIDA) tem buscado envolver a comunidade escolar na questão ambiental tendo como objetivo, em cada escola, construir a Agenda 21 Escolar, acompanhar projetos de educação ambiental e organizar a Conferência de Meio Ambiente na Escola.

Aqui destacamos a Conferência Nacional Infanto-Juvenil pelo Meio Ambiente (GNIJMA) Vamos Guidar do Brasil (Brasil, MEC, MMA, 2008). Essa pode ser considerada a maior e principal proposta e atividade para analisar e diagnosticar a práxis de educação ambiental. Nas escolas participantes, os estudantes debatem temas e propostas e definem ações. A III CNIJMA 2008-2009 propôs o tema "Mudanças Ambientais Globais" para ser debatido desde uma perspectiva sistêmica e integrada, com abordagens interdisciplinares e publicação do livro Mudanças ambientais globais: pensar + agir na escola e na comunidade.

Em junho de 2009, ocorreu em Brasília um encontro com educadores e educadoras ambientais das diversas regiões do país com o intuito de contribuir para um grande debate nacional sobre a interface Educação Ambiental / Mudanças Climáticas. Foram enfatizados o estímulo ao engajamento da sociedade e a disponibilização de aporte teórico aos educadores e agentes sociais para que atuem qualificadamente no combate ao aquecimento global. Isso se coloca tanto no plano educativo como na implementa- ção de agendas ambientais e projetos práticos (conservação de florestas, redução da pegada ecológica, energia, construções verdes, consumo sustentável, reciclagem, agricultura sustentável), na redução de nosso impacto no meio ambiente e na influência de políticas públicas que contribuam com a construção de sociedades sustentáveis. Esse encontro estabeleceu como ações prioritárias:

1 Mapeamento de ações, projetos e programas de EA no país e o estabelecimento de conexões entre seus resultados e a mitigação do aquecimento global;

2 Formação de formadores;

3 Inserção da EA em documentos, programas, fóruns e negociações que definem as políticas públicas de Mudanças Climáticas nos âmbitos nacional, estadual e municipal.

$\mathrm{O}$ documento ${ }^{9}$ indicou também que a EA deve aprofundar o debate junto à sociedade e governos, promovendo questionamentos e apresentando propostas articuladoras que agreguem conhecimento local às novas tecnologias, e estimulem o acompanhamento das ações de gestores e parlamentares.

Em setembro de 2009, o OG realizou em Brasília a "Oficina sobre EA no contexto das Mudanças Climáticas”, contando com quarenta participantes de universidades, sociedade civil organizada, representantes de instituições governamentais e convidados espe-

9 "Texto-base para a formulação de um documento referência na abordagem da Educação Ambiental em relação às Mudanças Climáticas”. Disponível em: <http://www. ecoar.org.br>. Acesso em: 25 nov. 2009. 
ciais. Em relação ao contexto nacional de mudanças climáticas, propuseram orientações para ações nacionais de EA, a partir dos eixos estruturantes da PNEA: comunicação, ensino formal (profissionalizante e extensão universitária) e ensino não formal (Brasil, MMA, 2010).

\section{Reflexões que se fazem necessárias}

O governo federal tem se interessado em qualificar o sistema educacional por meio de um maior envolvimento com o tema da Mudança Climática, efetivado com a organização de conferências e a produção de materiais didáticos. Todavia, o alcance dessas iniciativas é diferenciado em cada região do país. Dados locais e regionais para análise sobre os projetos e a implementação dos programas são ainda insuficientes. Por essa razão, somente os dados federais são registrados e, ainda, pouco socializados.

Do ponto de vista do processo de formação inicial e continuada para o ensino-aprendizagem, há uma enorme lacuna em termos de pesquisa, processos de intervenção e uso de metodologias inovadoras, e mais ainda em debates de profundidade. Nessa lacuna, a opção adotada é a relevância do ensino baseado no aprofundamento científico para o tema, como, por exemplo, através da confecção de materiais didáticos com conhecimentos acumulados sobre clima, correntes marítimas, composição da atmosfera, entre outros. E, desse modo, a promoção do ensino por meio de conteúdos que levem em conta a transposição didática dos conceitos científicos e do desenvolvimento de atitudes e valores éticos e estéticos.
No Brasil, a pesquisa científica ligada à Mudança Climática está adquirindo posição estratégica nos programas de ciência e tecnologia. Há uma combinação original entre educação e conhecimento científico. O foco principal tem sido relacionado aos desafios de adaptar e desenvolver programas educativos que incluam temas da diversidade regional; reconhecendo os ecossistemas complexos e diversificados, e o predomínio de um modo de vida urbano com todas as suas contradições, ligado ao consumo e, principalmente, ao aumento de uma lógica de insustentabilidade.

Considera-se que cada vez mais comportamentos, atitudes sustentáveis e valores éticos têm sido estimulados. Mas isso tem sido considerado de acordo com a prioridade dada nos espaços de educação formal e informal ante a questão de como pode a educação em diferentes estágios contribuir para alcançar a meta ambígua e discutível tanto do "desenvolvimento sustentável", quanto da utopia concretizável das "sociedades sustentáveis". Entende-se existir uma necessidade de pensar sobre o papel da educação para:

1 a promoção de aprendizagem social, construída ambientalmente - referente a processos cujo conteúdo e ênfase se voltam à reflexão crítica sobre a necessidade urgente de mudanças de atitudes e práticas individuais e sociais;

2 a ressignificação de valores, dentro de uma base cooperativa próxima ao pensamento crítico;

3 a habilidade para resolução de problemas; e 
4 a adaptação à vulnerabilidade das populações e da nossa espécie aos efeitos das mudanças climáticas, cujo foco nas necessidades poderia auxiliar as pessoas a tratar de forma mais crítica e responsável o ambiente em que vivem, tomando consciência dos cenários de um futuro de mudanças incertas.

A questão mais desafiadora é criar condições para que as iniciativas educacionais sejam estratégicas para realizar as mudanças necessárias para motivar os cidadãos a agir com responsabilidade em direção às metas de sustentabilidade; dada a existência de obstáculos de ordem moral, sociopolítica, cultural, sociocognitiva e psicossocial e barreiras estruturais e institucionais brasileiras relativas à mudança rumo à sustentabilidade, em suas múltiplas dimensões: ecológica, econômica, espacial, cultural, social (Sachs, 1993), política e institucional. As questões são complexas e não possuem respostas precisas, mas os programas educativos têm apresentado impactos consistentes referentes à multiplicação do tema e de sua importância para que a humanidade se mova em direção a uma cultura política e social de sustentabilidade.

\section{Algumas conclusões}

Paulo Freire (1997) dizia-nos que "não há o que fazer" é o discurso acomodado que não podemos aceitar. Até mesmo a produção de documentários que abordam as mudanças globais vem apontando os fatos científicos, os efeitos e responsabilidades das mudanças pela ação humana; mas ao mesmo tempo propondo estratégias e soluções para a vulnerabilidade das populações perante essa realidade, superando as fragilidades nas formas como o meio ambiente aparece na mídia - seja em função da superficialidade com que os assuntos são tratados ou da falta de espaço para abordagens mais complexas em torno das questões apresentadas (Lückman, 2007; Silva, 2005; Gamba, 2004).

No premiado e discutido documentário Uma verdade inconveniente, ${ }^{10} \mathrm{Al}$ Gore adverte-nos que "cada um de nós pode fazer escolhas que mudem isso", que pode ser complementada pela frase de Yann Arthus-Betrand, autor do documentário Home - Nosso planeta, nossa casa, ${ }^{11}$ de que "É tarde demais para sermos pessimistas. O que estamos esperando?". Portanto, cabe como dever e direito, tanto ao poder público quanto aos educadores e a toda sociedade - como recomenda o artigo 225, cap. VI da Constituição de 1988 - definir urgentemente nossas responsabilidades comuns, questionando quais são nossas opções: "Esperar para ver; Agir agora para reduzir os riscos; Agir como parte de uma estratégia de ações-chave para desacelerar o aquecimento!" (Miller, 2007). Isso significa que refletir sobre nossas escolhas quanto ao estilo de vida faz parte do exercício da cidadania ambiental global, visando a um mundo melhor para as atuais e futuras gerações.

Cortella (2009) ensina-nos que podemos viver segundo três preceitos éticos: "Quero? Devo? Posso?" e de que

10 Disponível em: <http://www.climatecrisis. net/>.

11 Produção Europa Filmes, 2009. Disponível em: <http://www.home2009.com.br>. 
diante dos dilemas éticos "somos livres para escolher a resposta". Segundo ele, com relação a nossa arrogância em nos considerarmos donos do planeta, convém lembrar que "nós não somos proprietários, somos usuários compartilhantes" (Cortella, 2009, p. 122). Diante desses princípios e valores caberia, com a licença do autor, acrescentarmos mais um, o "Eu faço!", resgatando com isso a intencionalidade política do ato pedagógico do educar, no sentido etimológico do "educere".

Para alcançar esse propósito, faz-se necessária uma instrumentalização teórica e metodológica do educador no processo de formação inicial e continuada, nas diferentes áreas de formação, para poder desenvolver as potencialidades do educando no que diz respeito ao conhecimento sobre as mudanças climáticas e às atitudes e valores envolvidos nesse processo, desde a educação infantil até a educação superior. Em função do Plano Nacional de Mudanças Climática, algumas iniciativas têm avançado, no sentido da discussão do tema na sociedade, como o Projeto Escolas Sustentáveis (CGEA-MEC), entendidas como "espaços educadores". ${ }^{12}$

Definimos alguns pontos que acreditamos sejam necessários a uma proposta educativa que transversalize essas questões no currículo escolar, nos processos de formação inicial e continuada e nas práticas sociais. Nesse sentido, os

12 Espaços educadores sustentáveis são aqueles que têm a intencionalidade pedagógica de se constituir em referências concretas de sustentabilidade socioambiental. Isto é, são espaços que mantêm uma relação equilibrada com o meio ambiente; compensam seus impactos com o desenvolvimento de tecnologias apropriadas, permitindo, assim, qualidade de vida para as gerações presentes e futuras. desafios mais importantes da educação ambiental associada à Mudança Climática no Brasil colocam a necessidade de:

- expandir o número de ações educativas, em nível local e regional, a partir das ações propostas nas Conferências e do Plano Nacional;

- produzir, ampliar e disseminar materiais didáticos adequados, cursos de formação docente e debates sobre questões pedagógicas, principalmente em relação ao que se pretende ensinar e aprender com relação à problemática;

- adaptar e desenvolver programas educativos que incluam temas da diversidade regional, como o caso do Brasil, e sobre o modo de vida urbano e sua lógica de insustentabilidade;

- criar espaços educadores de educação formal e informal para que a educação, em diferentes estágios, contribua para o pensamento crítico e a habilidade para resolução de problemas em direção à meta da construção de sociedades sustentáveis e para fazer frente às mudanças climáticas;

- implementar políticas públicas efetivas e integradas de meio ambiente, educação ambiental e educação;

- estabelecer acordos internacionais e apoio e recursos a programas de mitigação e adaptação ao aquecimento global, de acordo com as realidades e vulnerabilidades a que as populações estão expostas; 
- desenvolver parcerias efetivas na elaboração de programas e projetos com governos, universidades, redes e movimentos sociais, para manter e fortalecer a mobilização social e a disseminação de informações sobre as mudanças do clima;

- desenvolver algumas práticas individuais e coletivas de enfrentamento e mitigação dos efeitos das mudanças como: mudanças pessoais e grupais, nos padrões de consumo; aprofundamento teórico-metodológico sobre o tema; desvelamento dos jogos de interesse por trás das abordagens do problema na mídia e sociedade; articulação intra e interinstitucional para organização de ações coletivas e participação cidadã; desenvolvimento de atividades e materiais didático-pedagógicos para a abordagem desse problema (Deboni, 2006).

De uma perspectiva pedagógica e metodológica, há uma necessidade urgente de encontrar alternativas de aprendizagem para abordar um tema cujos cenários são negativos e problemáticos, como indicam os relatórios do IPCC, sem cair num ponto de vista catastrofista de imobilismo ou, em contrapartida, numa visão simplista a respeito de uma questão tão importante e crucial à sociedade contemporânea. A questão mais desafiadora, portanto, é criar condições para que as iniciativas educacionais sejam estratégicas para realizar as mudanças necessárias para motivar os cidadãos a agir em direção às metas de sustentabilidade. As questões são complexas e não possuem repostas precisas, mas os programas educativos têm apresentado impactos consistentes referentes à multiplicação do tema e de sua importância para a humanidade mover-se em direção a uma cultura política e social de sustentabilidade.

Na definição do por que, para que, como e com que ensinar sobre as mudanças climáticas, a educação ambiental pode valer-se da abordagem crítica e emancipatória (Loureiro, 2004; Loureiro; Layrargues; Castro, 2006), com ênfase na complexidade das interações e dos conflitos, relacionando ser humano, natureza e sociedade, e na reflexão e ação para minimizar os impactos das atividades humanas sobre os ecossistemas, que geram a crise ambiental. Essa abordagem crítica remete-nos novamente ao conceito de cidadania ambiental a qual envolve reflexão e ações de efetiva participação e de mobilização, com outras pessoas, na busca de soluções e/ou na prevenção de possíveis riscos ambientais a partir de "comportamentos ecologicamente desequilibrados" (Sato, 2003).

\section{Referências bibliográficas}

BRASIL. MEG. Formando Com-Vida - Comissão do Meio Ambiente e Qualidade de Vida na Escola: construindo Agenda 21 na Escola. Brasília: MEC, Coordenação Geral de Educação Ambiental, 2004.

BRASIL. MEG. MMA. Passo a passo para a Conferência de Meio Ambiente na Escola + Educomunicação: Mudanças Ambientais Globais/ Garcia Lopes Lima/Teresa Melo. Brasília: MEC, SECAD/ MMA, SAIC, 2008.

$$
\text { Agenda 21. Disponí- }
$$

vel em: <http://www.mma.gov. $\mathrm{br} / \mathrm{sitio} /$ index.php?ido=conteudo. 
monta\&idEstrutura $=18>$. Acesso em: 14 fev. 2009.

. MEC. Cadernos Secad 1. Educação Ambiental: aprendizes de sustentabilidade. Brasília, 2007. Disponível em: < http://portal.mec.gov.br/index.php?option $=$ com_co ntent \&view $=$ article \&id $=12504$ : cadernos -tematicos\&catid=190: setec $>$. Acesso em: 20 mar. 2009.

.DEA 2009: Balanço. Ações realizadas e em andamento. Brasília: MMA/DEA, 2010.55p.

- Ministério da Ciência e Tecnologia. Mudança do Clima. Vários. Disponível em: <http://www.mct.gov.br/index.php/ content/view/77650.html>. Acesso em: 29 jan. 2009

Programa Nacional de Educação Ambiental. 3. ed. Brasília: MMA, DEA, MEC, Coordenação Geral de Educação Ambiental, 2005.

CENTRO de Previsão do Tempo e Estudos Climáticos (CPTEG). Disponível em: $<$ http://mudancasclimaticas.cptec.inpe. br/>. Acesso em: 5 jun. 2009.

CORTELLA, Mario Sergio. Qual é tua obra? Inquietações propositivas sobre gestão, liderança e ética. 8. ed. Petrópolis: Vozes, 2009.

DEBONI, Fábio. Debatendo alguns mitos e chavões da Educação Ambiental (EA) brasileira. 2006. Disponível em: < http://www.adital. com.br>. Acesso em: 27 abr. 2007.

DIEGUES, Antonio Carlos S. Desenvolvimento sustentável ou sociedades sustentáveis. Cadernos FUNDAP, v. 6, p. 22-30, 1992.

FREIRE, Paulo. Educação como prática de liberdade. 30. ed. Rio de Janeiro: Paz eTerra, 2007.

.Pedagogia da autonomia: saberes necessários à prática educativa. Rio de Janeiro: Paz e Terra, 1997.

FREITAS, Mário. A década de educação para o desenvolvimento sustentável: do que não deve ser ao que pode ser. In: CONGRESSO IBERO-AMERICANO DE EDUCAÇÃO AMBIENTAL, 5., 2006, Joinville. Anais...
Joinville: Associação Projeto Roda Viva, p. 125-140, 2007.

GADOTTI, Moacir. Educar para a sustentabilidade: uma contribuição à década da educação para o desenvolvimento sustentável. São Paulo: Editora e Livraria Instituto Paulo Freire, 2008.

GAMBA, Izaltino César. Mediatização do meio ambiente: uma reflexão necessária. 2004. Dissertação (Mestrado em Educação) - UFSC, Florianópolis, 2004.

GAUDIANO, Edgar Gonzales. Campo de partida. Educación ambiental y educación para el desarrollo sustenible: tensión o transición? Revista Trayectorias, ano 8, n. 2021, jan./ago. 2006. Disponível em: <http:// trayectorias.uanl.mx/20y21/index.htm >. Acesso em: 10 abr. 2010.

.; CARTEA, Pablo Meira. Educación, comunicación y cambio climático: resistencias para la acción social responsable. Revista Trayectorias, v. 11, n. 29, p. 6-38, jul./dec. 2009.

IALEI - International Alliance of Leading Education Institutes. Climate Change and Sustainable Development: The Response from Education: a crossnational report from International Alliance of Leading Education Institutes. Denmark: IALEI, dec. 2009.

JACOBI, Pedro Roberto (Coord.); SILVA, Luciana Ferreira da; SULAIMAN, Samia Nascimento; NEPOMUCENO, Tiago Costa; RATINHO, Lesly Monteiro. Education and Climate Change in Brazil - Report for the IALEI Project - Climate change and sustainable development: The response from Education in Brazil, 2009. Disponível em: < http://educationforsustainabledevelopment.com/blog/ $>$.

LOUREIRO, Carlos F. B. Trajetória e fundamentos da educação ambiental. São Paulo: Cortez, 2004.

; LAYRARGUES, Philippe. P.; CASTRO, Ronaldo. S de.Pensamento complexo, dialética e educação ambiental. São Paulo: Cortez, 2006.

LÜCKMAN, Ana Paula. Educação, jornalismo e meio ambiente: leituras sobre 
a crise ecológica no contexto do aquecimento global. In: REUNIÃO ANUAL DA ANPED, 30., 2007, Caxambu. Anais... Caxambu, ANPEd. p. 1-16.

MEIRA, Pablo; SATO, Michele. Só os peixes mortos não conseguem nadar contra a correnteza. Revista de Educação Pública, v. 14, n. 25, p. 17-31, 2005.

MILLER, Tyler G. Ciência ambiental. 11. ed. São Paulo: Thomson, 2007.

NOBRE, Carlos A.; SALAZAR, Luis F.; OYAMA, Marcos; CARDOSO, Manoel; SACHS, Ignacy. Estratégias de transição para o século XXI: desenvolvimento e meio ambiente. São Paulo: Studio Nobel, 2007.

SAMPAIO, Gilvan; LAPOLA, David. Relatório n. 06: Mudanças Climáticas e possíveis alterações nos biomas da América do Sul. São Paulo: CPTC/INPE/IAE/ CTA, 2007. 25p.

SATO, Michele. Educação ambiental. São Carlos: Rima, 2003.

SILVA, Márcia Soares. Mídia e meio ambiente: uma análise da cobertura ambiental em três dos maiores jornais do Brasil. 2005. Dissertação (Mestrado em Comunicação e Cultura) - UFRJ, Rio de Janeiro, 2005.

PEDRO ROBERTO JACOBI, professor titular da Faculdade de Educação e do Programa de Pós-Graduação em Giência Ambiental, Universidade de São Paulo. Coordenador do TEIA-USP, Laboratório de Educação e Ambiente. Membro do GT 22 de Educação Ambiental da ANPEd.

E-mail:prjacobi@usp.br

ANTONIO FERNANDO S. GUERRA, professor do Programa de Pós-Graduação Mestrado em Educação, Universidade do Vale do Itajaí. Coordenador do Grupo de Pesquisa Educação, Estudos Ambientais e Sociedade - GEEAS. Membro do GT 22 de Educação Ambiental da ANPEd.

E-mail:guerra@univali.br

SAMIA NASCIMENTO SULAIMAN, mestre em educação, Faculdade de Educação, Universidade de São Paulo. Membro do TEIA-USP, Laboratório de Educação e Ambiente.

E-mail: samia.sulaiman@gmail.com

TIAGO NEPOMUCENO, mestrando em educação, Faculdade de Educação, Universidade de São Paulo. Membro do TEIA-USP, Laboratório de Educação e Ambiente. E-mail: tiagonepomuceno@gmail.com

Recebido em outubro de 2010 Aprovado em novembro de 2010 


\section{Mudanças climáticas globais: a resposta da educação}

$\mathrm{O}$ artigo aborda as respostas educativas perante as mudanças climáticas globais. Analisam-se as políticas nacionais e apresentam-se, como exemplo, resultados de pesquisa transnacional sobre mudanças climáticas e práticas educativas, da qual a Universidade de São Paulo foi parceira. O texto enfatiza que, do ponto de vista da relação entre o processo ensino-aprendizado, se observa uma enorme lacuna em termos de pesquisa, intervenção e debates em torno dos temas mais candentes. Entende-se que o maior desafio é promover um ensino baseado no aprofundamento científico sobre o tema, como, por exemplo, através da confecção de materiais didáticos interdisciplinares com conhecimentos acumulados sobre clima e mudanças globais. No Brasil, a pesquisa científica ligada às mudanças climáticas está adquirindo gradualmente uma posição estratégica nos programas de ciência e tecnologia, revelando uma combinação original entre educação e conhecimento científico. A questão mais desafiadora é criar condições para que as iniciativas educacionais sejam estratégicas para realizar as mudanças necessárias para motivar os cidadãos a agir em direção às metas de sustentabilidade, dada a existência de barreiras estruturais e institucionais relativas à mudança rumo a uma sociedade mais sustentável.

Palavras-chave: educação; mudança climática; Educação Ambiental; sustentabilidade; política pública

\section{Climate changes: the response of education}

The text presents the response from education facing global climate changes. It analyses the national policies and introduces as an example, the outcomes of transnational collaborative research on climate change and educational practices, in which the School of Education of the University of São Paulo was partner. The text shows that from an approach on the relation between teaching and learning, a large gap can be observed as to research, intervention and debates on the most glowing issues. It is considered that the main challenge is to promote learning based on more analysis on the issue, as for example, through the development of educational content with interdisciplinary knowledge accumulated on climate and global changes. In Brazil, scientific research linked to Climate Changes has been obtaining a gradual strategic role in science and technology programs, thus introducing an original combination between education and scientific knowledge. This most challenging issue is to create the necessary changes to motivate citizens to participate in initiatives that promote sustainability, given the structural and institutional barriers related to enable changes towards a more sustainable society.

Key words: education; climate change; sustainability, Environmental Education; public policy 


\section{Cambios climáticos: la respuesta de la educación}

El texto aborda las respuestas educativas frente a los cambios climáticos globales. Analiza las políticas nacionales y se presentan como ejemplo los resultados de investigación transnacional sobre cambios climáticos y prácticas educativas de la cual la Facultad de Educación da la Universidad de São Paulo fue socia. El texto muestra que desde el abordaje sobre la relación enseñanza-aprendizaje se observa un gran desfasaje en investigación, intervención y debates sobre los temas más importantes. Se considera que el principal desafio es de promover una enseñanza apoyada en un mayor examen científico sobre el tema, como por ejemplo, a través de la elaboración de materiales didácticos con conocimientos interdisciplinares acumulados sobre el clima y los cambios globales. En el Brasil, la investigación científica vinculada a los cambios climáticos viene adquiriendo gradualmente una posición estratégica en los programas de ciencia y tecnología, presentando una combinación original entre educación y conocimiento científico. La cuestión que desafía más es la de crear los cambios necesarios para motivar a los ciudadanos a actuar en aras de metas de sostenibilidad, dada la existencia de barreras estructurales $e$ institucionales relacionadas a los cambios rumbo a una sociedad más sostenible.

Palabras claves: educación; cambio climático; Educación Ambiental; sostenibilidad; política pública 